vas placed between the sides and canvas going from one end of the frame to the other, so that the curve is kept tight. When the rotary pulls come it is easy to encircle the patient with plaster.

It appears to me as I perform my experiments that when the patient is laid down on a curved surface with the spine upward there is some lengthening and untwisting, simply from position; and if to that is added a rotary pull, more is accomplished. I hope this answers the question about the way of putting on the jacket.

It is rarely that bone softening is not found. We cannot, of course, cut these patients up in order to see how soft the bones are. I was interested to see a patient whose case I have reported straighten up on the administration of thyroid extract. There must have been something to cause restoration of form. Nature tries to grow a thing straight when it has a chance, and with restoration of normal physiology that was what took place. I had an interesting case in a little girl with a slight curve that absolutely resisted treatment. I could push it straight, but it would not stay. I gave her thyroid and she braced up immensely. Then she suddenly went to pieces physically and it was discovered that she had old roots in her gums. They were removed and she has braced up and done well since. Her spine is about straight, and is, I believe, on the road to permanent recovery. That was a mild case, but it was extremely resistant.

\section{PAIN IN THE ARM: SUBDELTOID (SUBACROMIAL) B BURSITIS}

\section{A FURTHER STUDY OF ITS CLINICAL TYPES,} PATHOLOGY AND TREATMENT *

WALTER M. BRICKNER, M.D.

Fellow of the American College of Surgeons; Associate Surgeon, Mount Sinai Hospital; Captain, Medical Reserve Corps, U. S. Army NEW YORK

The statement may appear bold, even to a gathering of orthopedists, that most of the cases of persistent

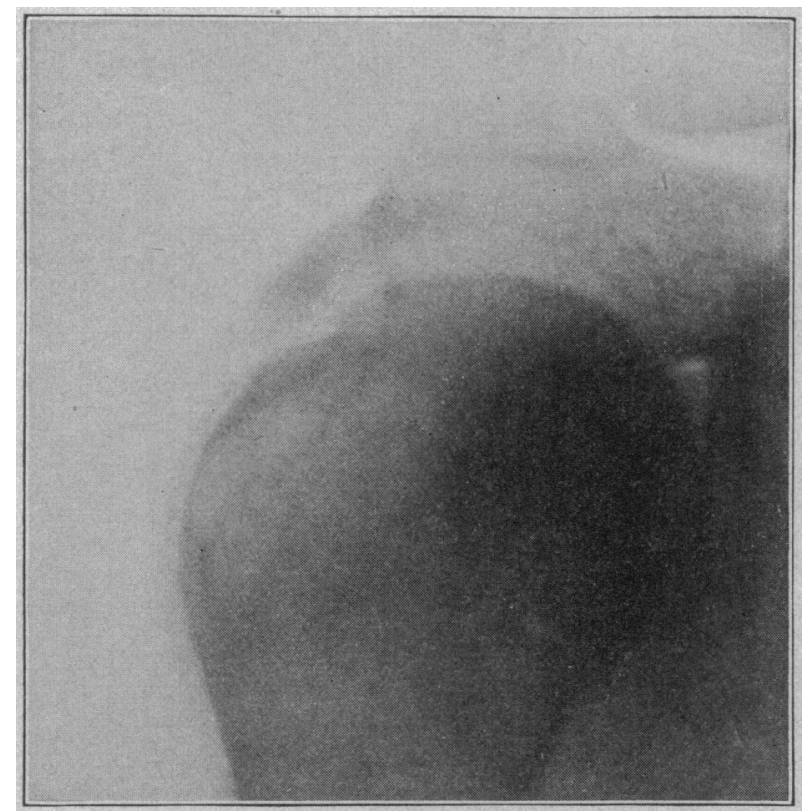

Fig. 1.-Large semifluid lime deposit beneath the bursa.

pain in the upper arm, so often treated for "rheumatism" and "neuritis," are surgical affections, at least in that they require mechanical treatment.

* Read before the Section on Orthopedic Surgery at the Sixty-Eighth Annual Session of the American Medical Association, New York, June, 1917.
In the absence of arthritis or of symptoms in other parts of the body, the diagnosis of rheumatism, as an explanation of pain in the arm, is quite untenable, and need not detain us.

Brachial neuritis is a real condition but a comparatively uncommon one. When well established, it

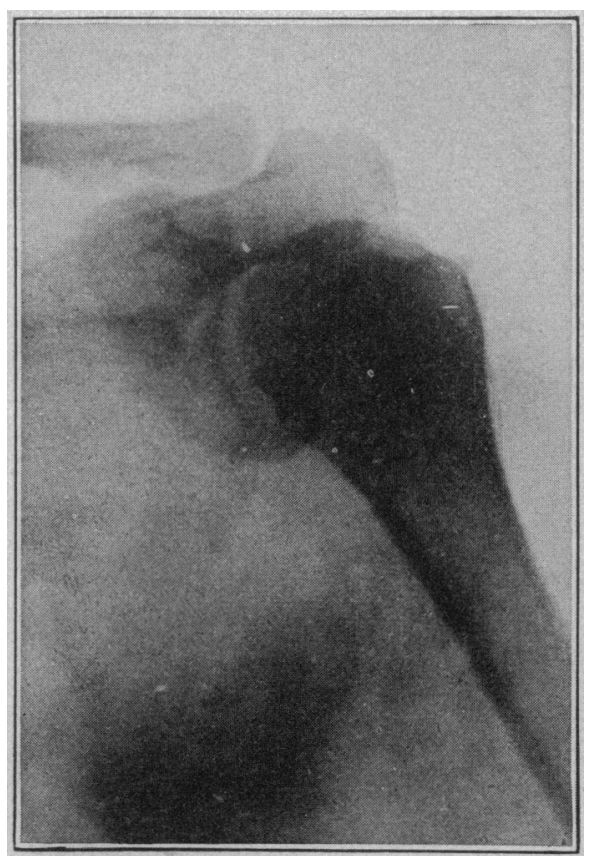

Fig. 2.- Very small deposit near the supraspinatus insertion.

should be marked by motor, trophic or sensory signs, as well as by nerve tenderness. In all cases it is important to determine, by careful examination, including roentgenography, whether the neuritis is not simulated or produced by some other lesion. Pain in the left arm, usually referred especially to the flexor aspects of the elbow and wrist, may be associated with an anginal condition and, as such, may be symptomatic, among other things, of tobacco poisoning.

Of the surgical conditions, aside from grosser and more evident lesions, that cause pain in the arm, we must bear in mind cervical rib, fracture of the greater tuberosity of the humerus (which may occur from comparatively mild internal as well as external violence), spontaneously reduced luxation of the shoulder, subluxation $^{1}$ of the shoulder (either of which may be produced, in some persons, by slight violence), mild sprain of the shoulder, periostitis of various origin, and neoplastic and inflammatory diseases of the bones, especially the humerus (among which chronic bone abscess, cortical or medullary, ${ }^{2}$ should be mentioned as an occasional cause of severe, persistent pain).

Far more common than any or all of these causes of pain in the arm and sometimes, but by no means always, also in the shoulder, is subdeltoid (subacromial) bursitis. It is, indeed, so often the cause of the complaint, that it should be thought of first.

In earlier communications ${ }^{3}$ concerning the pathology, pathogenesis and operative treatment of subdel-

1. Brickner, W. M.: Traumatic Forward Subluxation of the Shoulder: A Clinical Entity, Am. Jour. Surg., February, 1915.

2. Brickner, W. M.: Chronic Medullary Abscess of the Long Bones, Ann. Surg., April, 1917.

3. Brickner, W. M.: Prevalent Fallacies Concerning Subacromial Bursitis: Its Pathogenesis and Rational Operative Treatment Am. Jour. Med. Sc., 1915, 149, 351; Shounal Operative Treatment, Am. of Its Varieties and their Treatment, Interstate Med. Jour April, 1915 The Location and Cause of Lime Deposits As Med. Jour, April, 1915 Bursitis: "Excision of the Bursa," Am. Jour. Surg., April, 1916. 
toid bursitis, I presented the conclusions reached by several years of observation. These have been so much misquoted that I wish to restate and further elucidate some of them; and, especially, it is my purpose to describe the affection in its various clinical

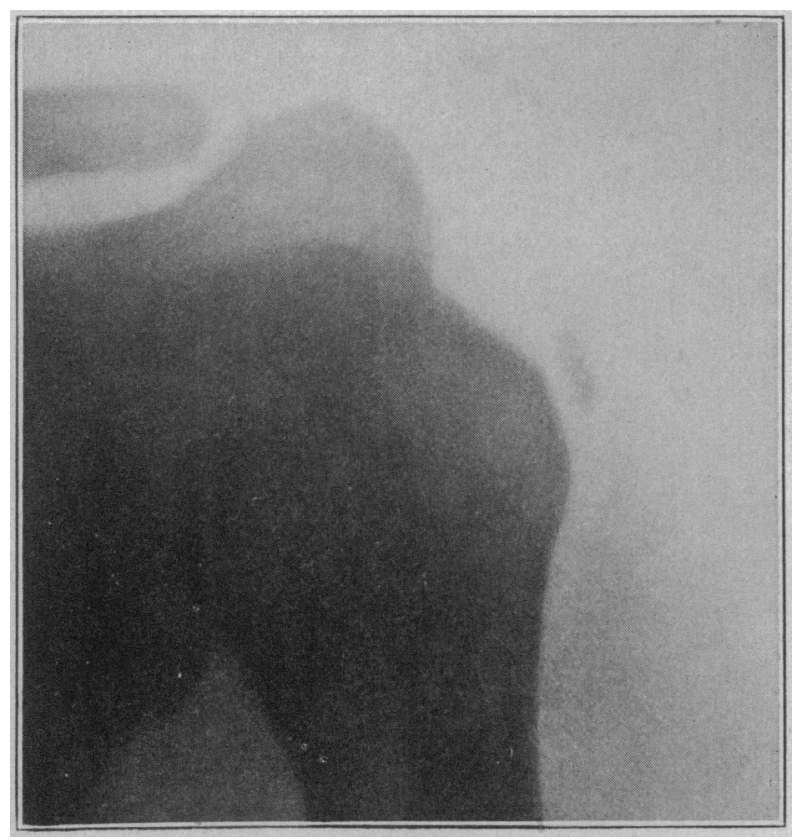

Fig. 3.-Deposit in the supraspinatus tendon.

aspects, its nonoperative treatment and what I believe to be the indications for operation. I shall exclude from consideration the uncommon tuberculous and metastatically suppurative subdeltoid bursitides.

\section{ETIOLOGY}

Although a history of injury or of muscular violence is often unobtainable, I believe that the immediate cause of subdeltoid bursitis is traumatic, usually a squeezing of the supraspinatus tendon (occasionally the infraspinatus) and the bursa between the acromion process and the greater tuberosity of the humerus when the arm is abducted. This injury may, and often does, happen from a fall on the outstretched arm or other external violence. More often it happens from internal violence, as in raising the arm to beat a rug, hanging from a car strap, etc. This squeezing of tendon and bursa between the bony surfaces is easily demonstrable at operation or on the cadaver by abducting the arm. In operation in acute cases, recent hemorrhage into and tear of the tendon are plainly to be seen. Codman ${ }^{4}$ reported three cases, and demonstrated, by operation in two of them, complete rupture of the supraspinatus tendon and tear of the bursal floor, from internal violence. Bucholz ${ }^{5}$ also reported a case, likewise demonstrated at the operation.

Small fractures of the greater humeral tuberosity, which, as I have said, may also be produced by muscular violence, are probably also associated with inflammation of the overlying subdeltoid bursa (which accounts in part for peristence of the shoulder disability after this injury, if it is not treated, as it should

4. Codman, Ernest: Complete Rupture of the Supraspinatus Tendon: Operative Treatment with Report of Two Successful Cases, Boston Med. Operative Treatment with Report
and Surg. jour., 1911, 164, 708 .

5. Bucholz, C. H.: Therapeutic Exercise and Massage, Philadelphia, Lea \& Febiger, 1917, p. 231. be, by abduction). Indeed, the lesion is much the same as subdeltoid bursitis without fracture - in one case there is a tear of the supraspinatus tendon above its attachment, and in the other, a tear through its bony attachment.

I believe there is another etiologic factor, at any rate, as far as concerns the commonly, but by no means always, associated subbursal deposit of lime and other mineral salts in or on the supraspinatus (occasionally the infraspinatus) tendon. This factor is some metabolic predisposition to the deposit of these mineral salts. I am of this belief for the following reasons: As far as I know, subdeltoid buritis occurs only in adults (in my cases, between the ages of 20 and 61 ); it occasionally is encountered first in one shoulder, then in the other; in some persons the deposit (or deposits) undergoes absorption, in others it persists; although a common affection, many persons using their arm in the same way, and subjected to the same influences, never develop it; it occurs among the muscular and athletic as well as the sedentary and asthenic, in females as well as in males; no other hypothesis explains why in some persons, within a day or two after a mild internal violence or an external injury, the roentgenogram will reveal this characteristic deposition of lime above the greater tuberosity of the humerus.

I have reason to believe that subacromial bursitis is neither infectious nor toxic in origin. Tissue specimens removed at operation in acute as. well as in chronic cases proved sterile. Even the sometimes liquid deposits of ten indistinguishable in appearance from pus contain no pus cells - only mineral salts, fat cells and detritus. Although in the acute stage there is sometimes a subfebrile elevation of tempera-

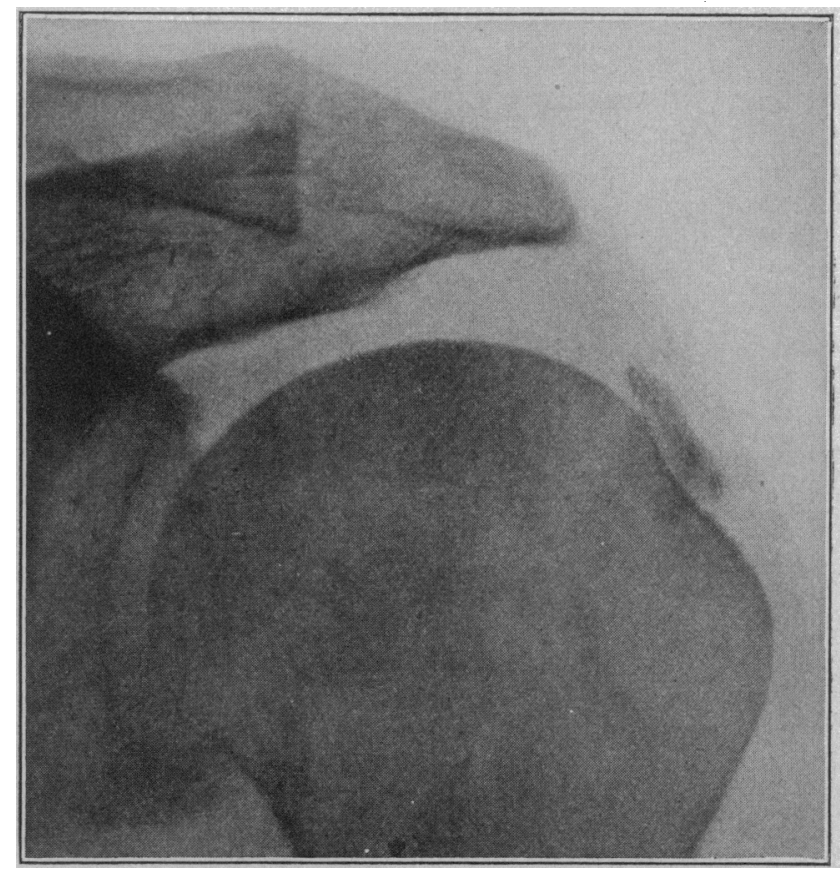

Fig. 4.-Deposit in the supraspinatus tendon.

ture, I have not found, in the more than 200 cases I have seen, any coexistent infection, nor have I been able to connect the lesion with any antecedent infection, tonsillar or otherwise.

I confess that my hypothesis of trauma and a biochemical predisposition as an explanation of subdel- 
toid bursitis and the subbursal lime deposit leaves much to be desired. What the metabolic fault is I have not learned. (It is a difficult laboratory problem.) Certainly there is no clinical evidence of gout. The occurrence of these lime deposits, and, indeed the

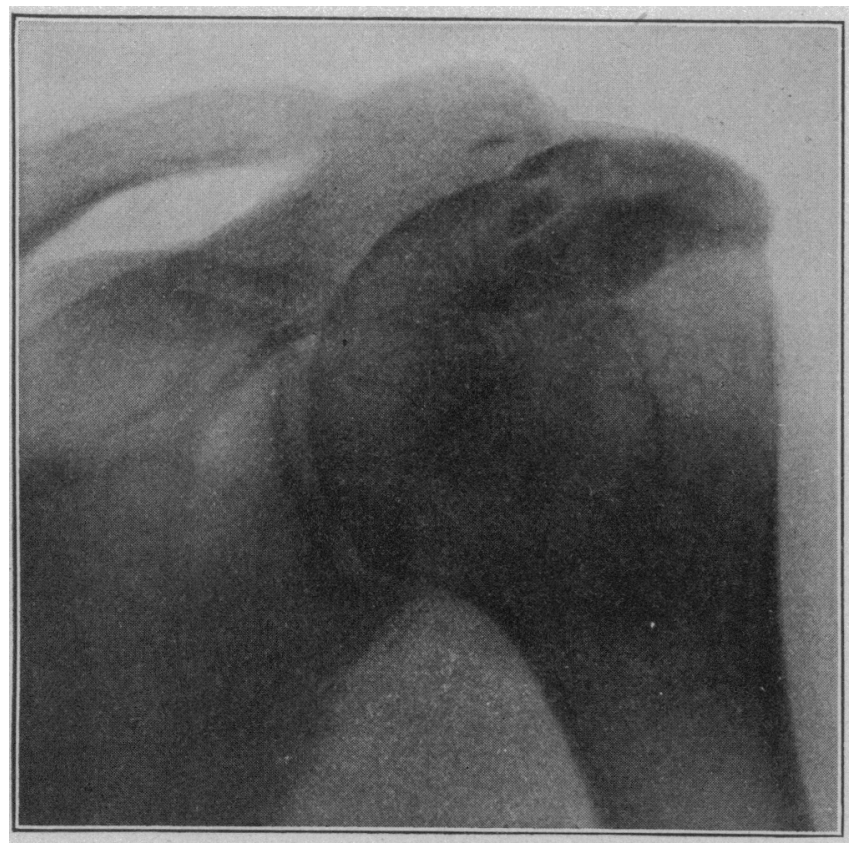

I ig. 5.-Very large, dry, caplike deposit, only partly in the tendon.

bursitis itself, have no exact analogue elsewhere in the body. It is a curious, and curiously common condition, and affords an interesting field for speculation and investigation.

\section{PATHOLOGY}

In all of the eighteen patients I have operated on. I found the same lesion in the bursa - adhesions between its two walls. These adhesions may be moderately long, or short and dense, gluing the two surfaces together over a limited area. They are always demonstrable if the operator is careful not to do what so many, I am sure, have done, namely, cut through the adherent floor and roof of the bursa with one incision. Beyond the area of adhesions, which is usually in the region of the greater tuberosity, the bursa can be freely entered with finger or instrument, and its free surfaces can be demonstrated. Here and there the bursal wall is sometimes thickened, but usually not much so. I have not encountered "villous" thickenings referred to in Codman's ${ }^{6}$ article. Sometimes there is a small amount of serum. This I have found locked in the subacromial portion of the bursa by the adhesions below it, and it is liberated when these are divided. In most cases, I have found no fluid accumulation in the bursa. Probably there is always a serous effusion at the outset, but it usually soon disappears.

The lime deposit is not in the bursa, or in its walls. It lies under the bursa, either wholly within the supraspinatus tendon, or on it, or partly within and partly on it. The tendon nuy have to be split to reveal the deposit or deposits, or the calcareous mass may be plainly seen lying in the tendon. Occasionally the deposit is in the infraspinatus tendon. Sometimes it

6. Codman, Ernest: Bursitis Subacromialis, or Periarthritis of the Shoukler Joint, Boston Med. and Surg. Jour., 1908, 159, beginning October 22 . will be found scattered about on the periosteum in the neighborhood of the greater tuberosity. Irrespective of the severity of the symptoms, the deposit may be small or large, dry and gritty or semifluid, single or multiple, near the insertion of the tendon or at a considerable distance from the tuberosity (Figs. 1 to 6). In early cases, there may be plainly seen a small transverse tear in the tendon near its termination, and a hemorrhage into the neighboring tendon tissue. The histology of the tendon lesion and of the lime formation has been studied from my cases, and adequately described, by Moschcowitz. ${ }^{\top}$ The lime deposition takes place, it would seem, as a result of necrosis of tendon tissue.

It can be seen from Figure 7 why so many surgeons have felt sure that they found the lime in the bursa. If the two bursal walls, adherent over the deposit, are divided at a single incision, the surgeon, believing he has cut only through the outer wall or "roof," will expose the lime mass, unless it is concealed in the tendon; on removing this mass he will encounter the broad supraspinatus tendon, which he believes to be the inner wall of the bursa. If, however, the operator will lift up the outer wall with tissue forceps and incise it carefully, and then divide the adhesions between it and the bursal floor, he will find that he can explore the interior of the sac without encountering the deposit. The latter will not be exposed until he has then separately cut through the inner wall or floor of the bursa, and not even then if, as is very common, the deposits are quite within the tendon.

I would emphasize again that the lime deposit takes place, not slowly, but very speedily after the injury.

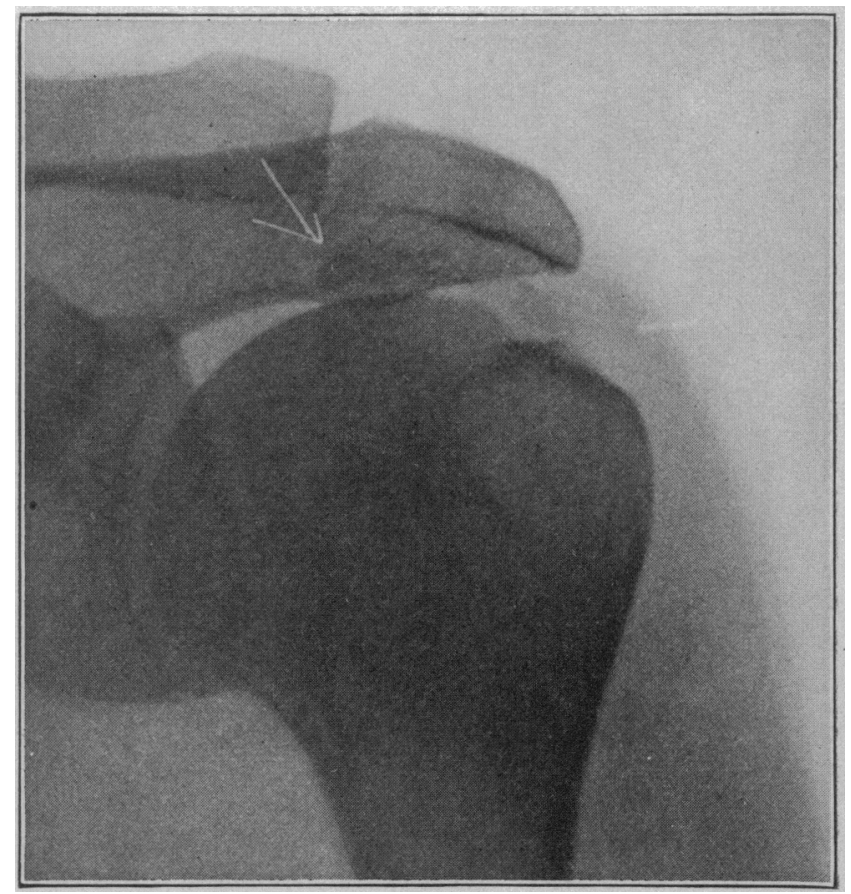

Fig. 6.-Multiple deposits in the supraspinatus.

In some cases it is slowly absorbed; in others it persists for years, perhaps for life. This, too, suggests some biochemical influence.

7. Moschcowitz, Eli: The Histopathology of Calcification of the Spinatus Tendons as Associated with Subacromial Bursitis, Am. Jour. Med. Sc., July, 1915. 


\section{SYMPTOMS}

The symptoms of subdeltoid bursitis are two: pain, and disability in shoulder movements.

Pain is present in almost all cases. It is usually referred to the upper arm, anteriorly or externally,

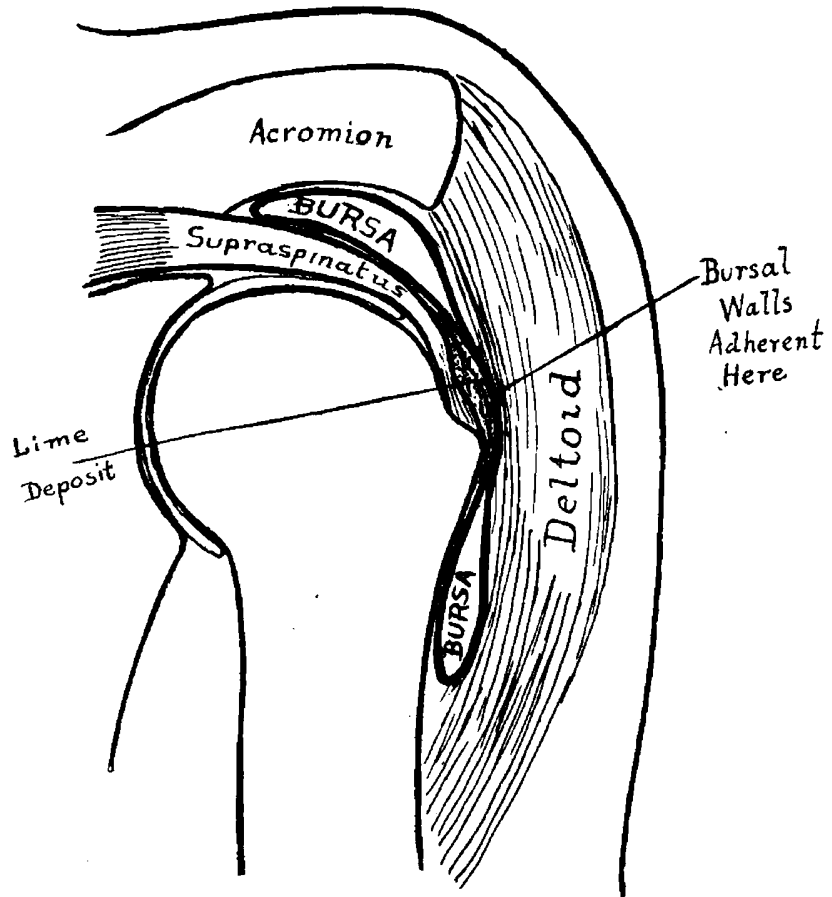

Fig. 7.-Diagram showing why many surgeons think they find the deposit in the bursa. Over the mass the two bursal walls are adherent and, unless separated by the operator, they are incised as one.

from the level of the deltoid insertion toward or to the elbow. Very often, but by no means always, it is referred also to the shoulder, usually its outer aspect. Sometimes it radiates into the forearm, the hand, the fingers or the neck. The pain may be fairly constant, or intermittent, or only on motion. Often it is worse at night.

Disability of movement may be entirely absent, especially in chronic cases. In the early stage, however, abduction, at least, is inhibited or painful. This movement and internal rotation are chiefly affected, but in varying degrees. The patient may be able to raise his arm only a little, or he may be able to abduct insufficiently to brush his hair. The interference with internal rotation may be very great or moderate; the patient may be unable to put his hand in his trousers pocket, or unable to reach behind his back, or unable to raise his hand on his back to the opposite scapula. External rotation is usually little affected; but sometimes is much inhibited. The arm can be swung backward and forward. There is no ankylosis.

\section{PHYSICAL SIGNS}

In the early stage there may be slight swelling due to serous effusion. In most cases, when the patient presents himself there is no swelling. On the contrary, there is often to be noted a flattening, due to atrophy of the deltoid. The supraspinatus and infraspinatus muscles may also be atrophied. Pressure on the bursa below the tip of the acromion process is sometimes painful, but it is usually painless. The only tender point that $\mathrm{I}$ find quite constantly is anteriorly, over the lesser tuberosity. When this point is very tender (comparison should be made with the opposite shoulder) it is fairly diagnostic in association with the symptoms described.

Roentgenography is important. If nothing is shown, it does not deny, rather it supports, the diagnosis of bursitis. If the shadow of a lime deposit is seen, however small it may be, the diagnosis is established beyond doubt. ${ }^{8}$ Finally, the roentgenogram may show some unsuspected lesion, namely, syphilis or tuberculosis of the head of the humerus, or a small fracture of its tuberosity (the latter, as I have said, clinically the same lesion as supraspinatus injury and, like it, probably also having a bursitis associated with it).

\section{CLINICAL FORMS}

Codman's ${ }^{6}$ classification into three types, "acute or spasmodic, subacute or adherent and chronic or nonadherent," is unsatisfactory from the anatomic side, for in all cases, acute or chronic, the pathology is, I believe, the same - an adhesive bursitis. We cannot recognize, therefore, a nonadherent and an adherent type, nor it seems to me, can we make a satisfactory distinction under the titles "subacute" and "chronic."

In my experience the cases present themselves in the following forms which, however, are not to be sharply separated: acute, "hyperacute," chronic, chronic with exacerbations.

In acute cases, pain and stiffness develop rapidly and reach a maximum in about three days. The pain is quite severe and constant, and subsides little or not at all at night. The arm can be only slightly abducted without great pain. There is spasm of the shoulder muscles, increased by attempted abduction or internal rotation, active or passive.

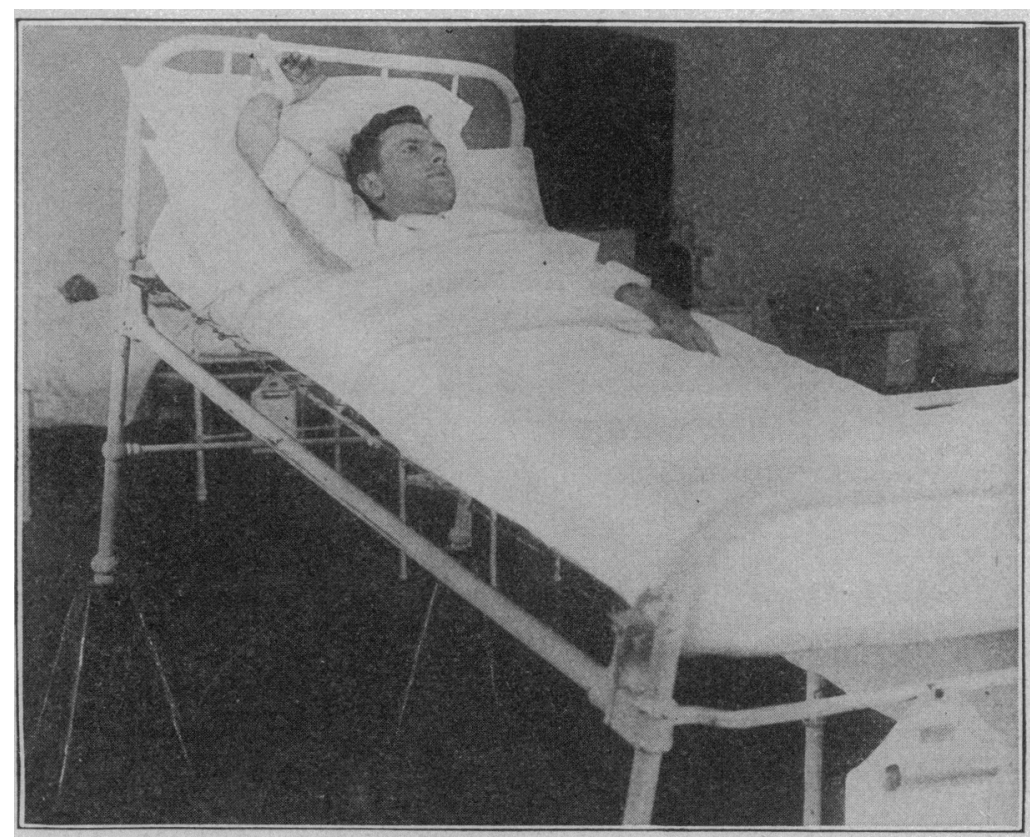

Fig. 8.- My easily regulable method of automatically restoring abduction in the Fig. 8.-My easily regulable
treatment of shoulder disability.

The term "hyperacute" I use to indicate not so much the rapid development of the symptoms as their severity. The pain is very great. The patient hugs his

8. Occasionally the tendon lesion exists without an overlying bursitis, but the symptomatology and treatment are the same. 
arm to his chest, and the slightest attempt to raise it causes severe spasm. There is a rapid development of atrophy of the deltoideus and the spinati. Radiation of the pain into the fingers, with this atrophy, may deceive even a neurologist into the diagnosis of brachial neuritis. Indeed, the early appearance of atrophy of these three museles suggests that there mav be some associated localized neuritis; disuse for a short period seems not quite sufficient to explain it.

In both the acute and the "hyperacute" forms, tenderness at the point $I$ have described is exquisite.

Acute subdeltoid bursitis may gradually subside completely. More often it passes into the chronic fom.

Chronic subdeltoid bursitis begins in the acute form, or is of the same severity throughout. The pain is often annoying rather than unendurable. It may be quite intermittent, varying in severity. Often it is present only on certain motions (as in pulling on an overcoat sleeve, or attempting to comb the hair). Abduction may be limited to 45,90 or 130 degrees; internal rotation may be much or little retarded. Passive movements are usually a little freer than active. External rotation is sometimes limited. In many cases the movements are perfect, but usually they are then more or less painful. Tenderness on pressure over the lesser tuberosity is usually present and often great. There may or may not be atrophy of the deltoideus and spinati.

This chronic form persists for months or years. Usually it subsides, with or without treatment, sometimes in spite of certain treatments. The lime deposit, if there is one, may gradually disappear completely.

The "chronic form with exacerbations" is of those cases, lasting for years, in which there is often a recession of symptoms, more or less complete, for long periods, but in which every few weeks or few months there is a severe exacerbation in which the symptoms approach those of the acute or even the "hyperacute" form.

\section{TREATMENT}

I am not inclined to place much confidence in electricity, baking, violet ray, internal medication or even massage. It is true, no doubt, that patients have recovered, by reason of such measures, or in spite of them. On the other hand, most of the patients referred to me have abandoned these treatments because their symptoms were unrelieved or even aggravated by them.

My first object, in the management of subdeltoid bursitis, is to overcome the abduction disability, the spasm (if there is any) and thereby, to a large extent, the pain. This I do by a simple automatic abduction method elsewhere described. ${ }^{9}$ I put the patient to bed supported on several pillows and with his arm raised as far as he comfortably can abduct it. A towel or bandage sling is passed from the wrist or ellow to the head of the bed, and this end of the bed is raised on blocks or chairs (Fig. 8). It will often be noted that as soon as the patient is comfortably recumbent he can abduct his arm more than when standing. As he gradually slides down in bed his arm correspondingly goes up; and it is no rare experience in a patient who has not abducted his arm more than 45 degrees in many months to find it thus fully and painlessly abducted in twenty-four hours. Usually it

9. Brickner, W. M.: A Simple Easily Regulable Method of Applying Airluction in the Treatment of Shoulder Disability, Med. Rec., New lurk, Jan. 2, 1915. takes a few days longer. If the patient cannot sleep with his arm in this sling, or cannot naintain that position continuously, he may intermit this gradual traction. Codein and acetyl-salicylic acid are helpful aids in overcoming the pain the first day or two. When passive abduction is thus fairly secured, active abduction is restored with it, and the pain soon disappears also in most cases. The abduction is maintained, and internal rotation is secured by after-treatment with Indian club exercises.

This plan of treatment is equally applicable to acute, "hyperacute," and chronic cases. It is of little or no value in chronic cases with no loss of motion. These cases, in which pain is the only symptom, are, in my experience, the most difficult to cure. Fortunately, the patients usually recover spontaneously.

I have come to the belief that most patients who have subdeltoid bursitis recover under this plan of treatment in bed with automatic abduction, or the trouble subsides spontaneously, though slowly. There are some, however, that do not thus recover and some that, though they may eventually do so, meanwhile suffer so much pain, loss of function and interference with occupation that operation is to be recommended as a means of prompt cure. I would therefore advise operation in the following cases: 1 . In the chronic form with exacerbations. These patients have been through all sorts of treatment for years; their sufferings during the periods of exacerbation are severe; they show no tendency to spontaneous recovery. 2 . In acute, "hyperacute" and chronic cases in which the automatic abduction in bed fails to restore function and to relicve pain and spasm.

The operation I employ I have previously described. ${ }^{10}$ In consists in : splitting the deltoid; raising the outer wall of the bursa from the inner and incising it; dividing all adhesions in the bursa; incising and retracting the floor of the bursa; removing the deposit, if extratendinous, and suturing any tear in the supraspinatus tendon; or incising the tendon wherever indicated by the roentgenogram and excising the deposits.with surrounding tendon fibers, and reuniting the tendon with chromicized catgut (if the defect is not too large); suturing the floor of the bursa with a fine running catgut stitch; anointing the interior of the bursa with a thin layer of petrolatum; suturing the outer wall of the bursa; suturing in layers, without drainage, the deltoid muscle, the deltoid fascia and the skin; abducting the arm in plaster of Paris for about a week.

The petrolatum may not be important. The reconstruction of the bursal walls is not essential, but it aims at an anatomic operation. The abducted position is also not essential, but $I$ believe that it shortens the after-treatment, which consists in Indian club exercises and other devices to restore internal rotation and full abduction.

All the patients thus operated on have been promptly relieved of pain and early restored to full activity. In only one patient, a physician, was there any complication - a brachial phlebitis which retarded his recovery a few weeks.

In one case of chronic bursitis without any lime deposit, in which the pain and disability continued, with exacerbations, for years, division of the adhesions and abduction for one week were followed by permanent cure. This is the only case without lime deposit in which I have operated. It illustrates, first,

10. Brickner, W. M.: Footnote 3, first reference. 
that the roentgenogram of a deposit is not essential to a diagnosis of subdeltoid bursitis and, second, that division of the adhesions (and placing petrolatum in the bursa) will effect a cure when conservative measures fail, even in the absence of the lime mass.

30 West Ninety-Second Street.

\section{ABSTRACT OF DISCUSSION}

Dr. Eli Moschcowirz, New York: [Dr. Moschowitz demonstrated lantern slides made from specimens of portions of supraspinatus tendons submitted by Dr. Brickner for pathologic examination.] The lesion is a tendonitis, characterized by necrosis or hyaline degeneration of the tendon with secondary calcification, and a reactive granulation tissue around these areas of necrosis or calcification. The morphologic changes parallel the duration of the disease; thus, in long standing cases abundant scar tissue is present, while in early cases the granuiation tissue is richly cellular. I believe that the necrosis was due to actual death of tendon tissue and was not of hemorrhagic origin because blood pigment was entirely alsent. The necrosis is, in all probability, due to cutting off of the meager blood supply of the tendon consequent on the tratma. Calcification inevitably follows in those portions of the tendon that have undergone necrosis or hyaline degeneration. This is the usual consequence in other tissues of the human frame. The remarkable feature is the early incidence of the calcification. We are accustomed to think of calcification as occurring only after the tissue has been dead for some time, but in the cases that Dr. Brickner reports calcification occurs as early as forty-eight hours after the onset of symptoms. The only possible explanation of this early calcification is found in the results of the experiments of Litten and Schujeninoff, who found lime twenty-four hours after traumatic necrosis of the kidney and muscle, respectively. Perhaps the peculiar predilection to early calcification may be due to certain biochemical products in the tendon itself (collagen?).

Dr. J. Bion Bogart, Brooklyn: I want to say a word from the standpoint of one who suffered for four and a half years and has not been cured. Four and a half years ago I had a surgical infection through the index finger which resulted in metastatic infection of the shoulder joint and which was opened and drained and afterward had extension for four weeks. I was able to work after that, though I still have limitation of motion in the joint, but not ankylosis. My chief symptom, in addition to limitation of motion, is pain, which is not present except on motion or pressure. One of the most serious difficulties that I labor under is inability to turn on my left side to sleep at night. I cannot lie on that shoulder because the pressure causes too much pain. When I raise my arm it causes pain, which runs down the arm. In my own case, so far as I know, there was no injury. I think that the same infection that caused the metastasis to the shoulder joint produced the bursitis, which was not, however, recognized at the time. Following recovery from the early symptoms, I had treatment with baking and massage for two months, after which I gave it up, because I did not gain anything in motion and the treatments were followed by pain. This kind of treatment did not seem to do me any good, but harm, if anything. I have done nothing since for the last four years. I was roentgen rayed at the time of my infection, and since then, a year and a half ago. The gentleman who did it later, Dr. Wasch, is here. There was no calcareous deposit then, and, so far as I know, there is none now.

Now what is it that causes my pain? I have none when the arm is at rest, but only on pressure or motion. If adhesions cause it in the cases in which there are no deposits, I think they are sure to be reformed after operation; and I do not see how relief can come from the operation in such cases as mine. I do not see, either, how relief could come from forcible stretching of the arm upward. It cannot be done immediately, but only gradually; but, as the scapula moves with the arm, I do not see how benefit could come in that way.
Dr. Fred J. Fassetr, Seattle: Have any of those present seen the very rapid disappearance of these lime deposits? I have seen one case, reported by Dr. Ristey of Boston, and also one of my own, in which the disappearance of the calcification was so rapid as to cause a question as to the authenticity of the plates.

Dr. Mitton G. WASCh, Brooklyn: I have been fortunate enough to have made roentgenograms in a great many of these cases. Within the last six months I have seen twentyfive. It has always been my custom to make roentgenograms of the opposite shoulder for comparative study, and I have been surprised, a good many cases, to find lime salts in the opposite shoulder, in which the patient had not complained of any symptoms either at that time or previously. I, therefore, feel that the statement that deposits of lime salts form in one or two days is doubtful. I think when the patient complains of symptoms due to subacromial bursitis the probability is in most cases that the calcium has already been deposited and that the condition and suffering are from an acute exacerbation of a chronic calcifying bursitis.

Dr. Willis C. Campgell, Memphis, Tenn.: I should like to emphasize a point that Dr. Brickner made in his paper, that mild trauma is the frequent cause of this condition; and also that this injury may be overshadowed when other parts are seriously damaged. I had such a case in a young man. The injury was received in an automobile accident and he did not recognize the trouble in his shoulder for six weeks. By that time there was beginning atrophy. I did not see him for six months after the accident; then there was extreme atrophy and considerable trophic disturbance in the arm with abduction totally limited. Relief was soon given by simple abduction in a plaster cast, followed by massage, etc.

Dr. HeinRICh Wolf, New York: I have had occasion to treat a few hundred cases of subacromial bursitis and should like to know what stand Dr. Brickner takes now regarding the infectious origin of some of these cases. We know that a great many are traumatic.

With particular reference to the remarks of the last speaker, I would say that I have noticed a great many cases following Colles' fracture of the wrist. If a patient falls on his hand and gets a fracture of his wrist, the pain in his wrist is so severe that he neglects a probable slight injury in the shoulder joint. I have seen about twenty cases of this in the dispensary of the Mount Sinai Hospital, in which subacromial bursitis developed five or six weeks after the injury to the wrist.

Then I have seen patients get a similar condition after infectious conditions in the hands. I cannot explain in what way an infection in the hand can be followed by subacromial bursitis, but $I$ have seen it too often to consider it an accident. I hope that Dr. Brickner will be able to answer this question, particularly about the infectious condition. I have seen lately quite a number of cases of acute bursitis in which I was positively able to trace it to infection in the teeth. I know that Dr. Brickner does not believe that this is possible; but I mean, of course, only a certain number of cases. I want to say that I have seen other etiologic factors, but that in these particular cases removal of the teeth relieved the pain.

Dr. Јон n Dunlop, Washington, D. C.: In some cases with a lime deposit in which operation was performed I found absolutely no adhesion. I should like to ask Dr. Brickner whether he considers that all cases of lime deposit have subacromial bursitis. I think in most cases they are quite separate conditions.

I believe there is nothing in Dr. Brickner's exposition, other than what Dr. Codman brought out in his paper in 1908 . I have seen four cases of such deposits, in one of which operation was performed. In the first three cases that I saw operation was refused. I put the arm up in the abducted position and the patients got as well as any other cases of subacromial bursitis that $I$ have seen. The fourth case was in a man who had so much pain that half a grain of morphin every four hours would not quiet him. I tried to put his arm up in the abducted position under nitrous oxid anesthesia. This increased the pain so markedly, however, that I operated. Dr. Brickner showed that he found adhesions. I found no adhesions in this case. I cut down to the bursa and 
demonstrated it to be as large, as Dr. Codman explained, as the palm of the hand. I saw the white mass shining through the base of the bursa and cut down on this and was able to scoop it out with a spoon. It was of the consistence of a soft toothpaste and quite white. I sent it to the laboratory of the Army Medical School and hoped to get a report on it from there; but it was lost. I did, however, get a negative bacteriologic report. I passed a probe well up within the sheath of the supraspinatus muscle and was sure that I was within it. The lower and upper surfaces of the bursa were closed and the man got a perfect functional result.

The day after I heard Dr. Brickner read his paper I had a case in an officer in the Marine Corps who refused operation. I put his arm up in abduction and he got well. Later, he had symptoms in the other shoulder, of which I had not made roentgenograms when I operated on the first shoulder. I treated that, and he got so well that he now plays tennis and golf every day. He still has the deposit in the shoulder, eighteen months after the diagnosis was made.

I do not agree with Dr. Brickner that these deposits occur within a few hours. We have no evidence that they do, for we do not take roentgenograms of our patients before. I think the symptoms come on from some trauma due to the deposit which may have been there for weeks, months or years before. It seems to me, from my four cases, in three of which there was no operation, that these patients will get well without operation.

Dr. Walter M. Brickner, New York: Dr. Dunlop reports that he found a lime deposit in the tendon in a case in which there were no adhesions in the bursa. That does occur. I referred to it in an earlier paper as "calcareous tendinitis without bursitis." I do not wish to claim anything that leiongs to Codman, who was the first to suggest, in thrce cases, that the deposit is under the bursa. He speaks of it, however, as wenlike and cystlike, which it is not; and the conception of it as being often wholly within the tendon was not brought forth by Codman.

Concerning the rapid formation of the deposit, you are right in questioning my statement. The deposit may have been there before the symptoms called for a roeitgenogram. but I have, not only once, but several times, found patients who, two days after a fall on the shoulder, or a lurch of the body while hanging to a car strap, showed this deposit in the picture, patients who never previously had any symptoms, but who had the characteristic symptoms after the injury. In one such case, "hyperacute," I operated a few days after the injury. The deposit had been shown by the Roentgen ray three days after the injury. I found a fresh tear in the ecchymosed supraspinatus tendon, and the lime deposit in the tear and in the surrounding bruised tendon tissue. Whether I am right in the assumption of very rapid lime formation, I am willing to leave open. I have not seen rapid disappearance of the deposit. I have seen it occur within two to six months, liut not earlier.

I believe that I have fully answered Dr. Wolf's question. Occasionally one encounters metastatic suppuration in the bursa in connection with a septic process; but I believe that the cases of subdeltoid bursitis of which we have been speaking are not infectious in origin. Sometimes a man reports an isolated case in which the patient had tonsillitis previously, and then be jumps to the conclusion that the tonsillitis was the cause of the disease. That is unscientific.

I hope that I have made it clear that these patients often get well without operation.

School Medical Inspection and Local Government.-Were it not for the fact that the Cumberland schools and the county schools are one unit, we might be able to see our way clear to establish medical inspection of schoolchildren, but this cannot be under the present system of one school unit for the entire county. Ample laws now exist that would enable the county school commissioners to establish this inspection, but somehow or other, as with all other advanced movements, some public bodies are slow to comprehend their value. We urge all parents to advocate medical inspection for the sake of their children.-Health Bullctin, Cumberland, Md.

\section{THE USE OF BAKERS' YEAST IN DIS- EASES OF THE SKIN AND OF THE GASTRO-INTESTINAL TRACT *}

PHILIP B. HAWK, PH.D.

FRANK CROZER KNOWLES, M.D.

MARTIN E. REHFUSS, M.D.

PHILADELPHIA AND

JAMES A. CLARKE, M.D. NEW YORK

With the Collaboration of Olaf Bergeim, Ph.D., H. Rodell Fishback, M.D., Sc.D., Clarence A. Smith, Ph.D., and Robert A. Lichtenthaeler, M.S.

That yeast possesses curative properties was appreciated in the olden times. Hippocrates recommended its use in leukorrhea, and the monks used it for the treatment of plague. Not until the middle of the nineteenth century, however, did the medical profession look favorably on its use. About that time, it was used successfully in furunculosis, anthrax and diabetes.

TABLE 1.-CLASSIFICATION OF NINETY-ONE DIFFERENT CASES IN WHICH THE YEAST TREATMENT WAS USED

\begin{tabular}{|c|c|}
\hline Type of Case & Number \\
\hline 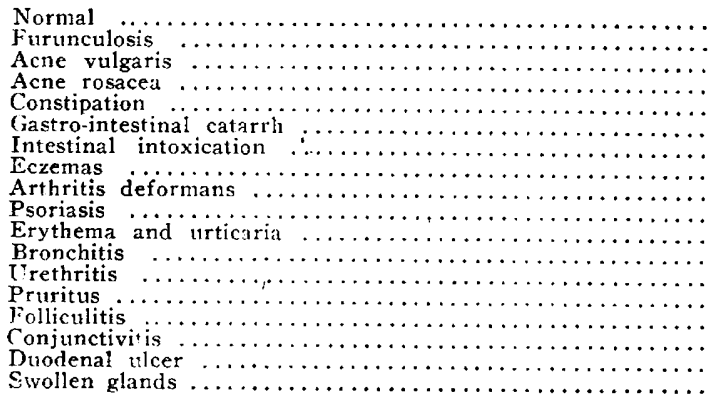 & $\begin{array}{r}15 \\
17 \\
17 \\
8 \\
10 \\
3 \\
1 \\
5 \\
1 \\
4 \\
1 \\
2 \\
2 \\
1 \\
1 \\
1 \\
1 \\
1\end{array}$ \\
\hline 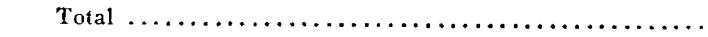 & 91 \\
\hline
\end{tabular}

Later it was shown to be effective in diseases of the skin, suppurative processes, diseases of the respiratory passages, gastro-intestinal diseases, vaginitis, general infectious diseases, etc. - In fact, for an interval of many years yeast was used as a curative agent in a long list of widely differing disorders. Then came a reaction, and yeast was used comparatively little by the medical profession during the latter part of the nineteenth century.

In 1899 the researches of Brocq $^{1}$ emphasized anew the therapeutic importance of yeast, and from 1900 to 1907 many important contributions were made to the sulject of yeast therapy. For the last ten years, however, comparatively little attention has been paid to the use of yeast in medicine.

Owing to the fact that the great majority of the yeast researches have been carried out with brewers' yeast or various dried yeast preparations, and since several investigators have asserted that bakers' yeast was not a satisfactory therapeutic agent, we have thought it of importance to make a comprehensive study of the curative value of ordinary bakers' yeast,

* From the Laboratory of Physiological Chemistry of Jefferson Med. ical College, the Philadelphia General Hospital, and the Roosevelt Hospital, New York. 